\title{
An Evaluation of Green Manufacturing Technologies Based on Research Databases
}

\author{
Sung-Hoon Ahn ${ }^{1,23 t}$ \\ 1 Department of Mechanical and Aerospace Engineering, Seoul National University, 301-1205, Seoul 151-744, South Korea \\ 2 Institute of Advanced Machinery and Design, Seoul National University, 301-1205, Seoul 151-744, South Korea \\ 3 Department of Mechanical Engineering, University of Washington, Stevens Way, Box 352600, Seattle, WA 98195, USA \\ \# Corresponding Author / E-mail: ahnsh@snu.ac.kr, TEL: +82-2-880-7110, FAX: +82-2-883-0179
}

KEYWORDS: Green Manufacturing Technology, H-Index, Research Database, Web of Science, Journal Citation Report, Technology Hype Cycle, Impact Factor

\begin{abstract}
The International Journal of Precision Engineering and Manufacturing-Green Technology (IJPEM-GT) was inaugurated in order to foster knowledge sharing and collaboration of researchers in the field of "green manufacturing." While emerging technologies can be evaluated by business points of view such as Hype Cycle of Gartner, in this paper, journals and research areas in green manufacturing were evaluated by using research databases such as Web of Science and Journal Citation Report. Using impact factor and the number of published papers as key parameters, journals in subjects of Engineering-Mechanical, Engineering-Manufacturing, Engineering-Environmental, and Energy and Fuels were compared. From the point of researchers, the H-Index and the number of published papers were evaluated for journals and technologies in green manufacturing. The H-Index of journals or research areas was proportional to logarithm of the number of papers, and linear trend lines were observed from the data. The journals in green technology show higher gradient in the trend line compared with the journals in manufacturing and environmental areas. In addition, a Four Stage Model (early-emerging-developed-saturated stages) of technology development was proposed.
\end{abstract}

Manuscript received: December 4,2013 / Accepted: December 24, 2013

\section{Introduction}

Two important challenges in 21 st century manufacturing can be identified as environmental shift and deficiency of energy and resources. The Keeling Curve shows dramatic increase in $\mathrm{CO}_{2}$ concentration in air, which reached $400 \mathrm{ppm}$ in 2013 compared with $315 \mathrm{ppm}$ in $1958,{ }^{1}$ and this is expected to result in strong greenhouse effects. Besides many evidences of research papers, recently National Geographic released a map predicting sea level withdrawal of the world in the future in which a large portion of major cities such as New York, Miami, and Shanghai as well as highly populated regions will be greatly damaged if icecaps in polar areas are caused to melt out. $^{2}$

Another critical change is energy and resource deficiency mainly due to the increase in world population from 70 billion in 2011 to 100 billion at the end of this century. ${ }^{3}$ Rapidly improved standards of living in developing countries will further worsen this problem. The issue is not merely productivity which is already too high leading to oversupply in many industries, but also in how to supply raw materials and energy to manufacture and operate largely increased demands on products and energy. For example, more people will want to run automobiles in developing countries, and more materials and energy to make automobiles as well as fuel to run automobiles will be required.

Today, many industrialized countries enjoy affluent products, food, energy, etc., but current preparatory efforts for coming environment/ energy impacts by local governments and international organizations are not effective enough in order to remove or reduce the problems. The next decades will be critical to turn the trend or mega trend of disasters favorably to human lives. ${ }^{4}$ Reflecting the urgency in energyenvironment-resource issues, research areas on sustainable technologies are gaining more ground.

Among energy consumption of the world, industry consumes about $33 \%$, and transportation, heating/cooling of building consumes $28 \%$ and $39 \%$ respectively. ${ }^{5}$ Along with the energy consumption, release of toxic materials and wastes during manufacturing processes also give negative effects on the environment. Although the importance of manufacturing-related technologies to future lives of humans seems critical, unfortunately, few technical journals have been accommodating research results in these fields. Thus, International 
Journal of Precision Engineering and Manufacturing-Green Technology (IJPEM-GT) was initiated and split from the International Journal of Precision Engineering and Manufacturing (IJPEM) in order to foster knowledge sharing and collaboration of researchers in "green manufacturing." To cover significant subjects in energy-environmentresource saving based on manufacturing technology, the following five main topics were selected for the journal:

1. Energy Saving and Waste Reduction in Manufacturing Processes

2. Manufacturing of New and Renewable Energy Devices

3. Design and Manufacturing of Green Products

4. Materials for Green Manufacturing

5. Management and Policy for Sustainable Manufacturing

These topics were summarized from a series of International Symposium on Green Manufacturing and Applications (ISGMA) which was held in Seoul (2011), Jeju Island (2012), and Hawaii (2013) ${ }^{6,7}$ More details on topics and sub-topics are available at the journal website (http:/ /www.springer.com/journal/40684). In this paper, journals and research areas in green manufacturing were evaluated by using research databases.

\section{Evaluation of Research Areas on Green Manufacturing Technologies}

Different levels of abstract are available to evaluate significance of technologies in general. For example, the Hype Cycle published by Gartner Group shows expectation of people to the emerging technologies, and it also shows on which development stage certain technology is moving. ${ }^{8}$ The assumption in this evaluation method is that a technology develops from innovation triggers, peak of inflated expectations, trough of disillusionment, slope of enlightenment, and finally reaches a plateau of productivity where the technology matures and the market recognizes it as a profitable technology. Fig. 1 shows the overall summary of some green technologies based on this Hype Cycle. For example, the additive manufacturing, or rapid prototyping (RP) has been introduced in 1980's and is at the 'peak of

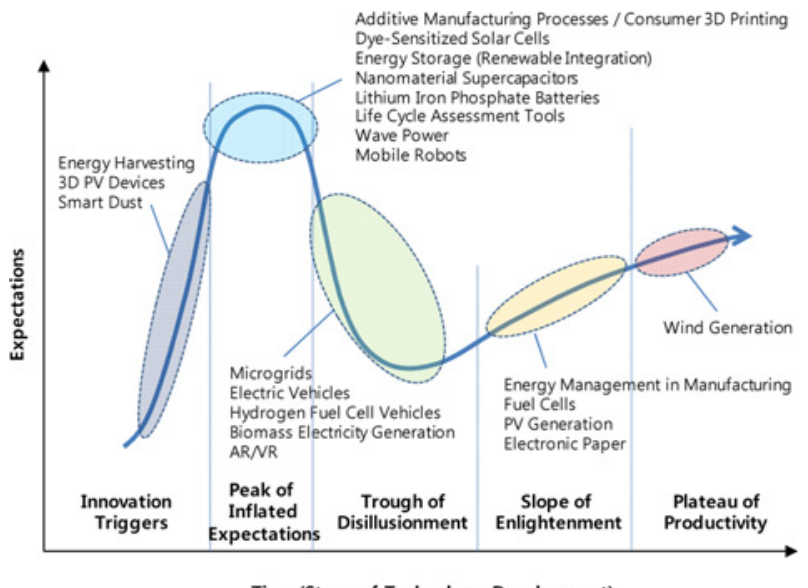

Fig. 1 Hype Cycle 2013 is modified and redrawn to show the development stages of research areas related to green manufacturing technologies ${ }^{8}$ inflated expectation' stage in 2013 receiving high popularity from even laymen who do not understand technology. Later, the expectations decrease as negative aspects of a specific technology are revealed, but eventually it will take off and become a matured business. Some technologies may diminish before they reach the matured 'plateau of productivity,' due to many reasons.

To evaluate the importance of certain technologies from the point of researchers, however, data from journal publications or research databases seems more reasonable. In this research, three assumptions on evaluation are made as follows:

- The supply and demand of research outcome are mainly based on free will of the researcher similarly in the free market (invisible hand works in this technology market to make equilibrium in supply and demand)

- The number of journal papers are proportional to the 'importance' of the research area

- The number of citations are proportional to the 'attention' received by researchers

Fig. 2 shows a comparison between research areas related to current IJPEM (engineering-manufacturing and engineeringmechanical) and green technologies such as engineering environment and energy \& fuels. The $\mathrm{x}$-axis represents the total number of journal papers in each research area during two years (2010-2011) obtained by Journal Citation Report, ${ }^{9}$ and the y-axis shows aggregate impact factor, which is calculated from the total number of citations during two years divided by total number of papers published during two years. The size of circle represents the number of journals in each area. While the total number of journals in both manufacturing and mechanical engineering is compatible to the total number of journals in environmental and energy/fuel areas, more papers are published and the aggregate impact factor is more than twice higher for the energy-environment areas than mechanical-manufacturing areas. Combining manufacturing technologies to the energy-environment technology may produce significant synergy effect not only for advancement of green technology, but also for the initiation and development of new engineering journals covering this almost empty territory which is not covered by existing journals.

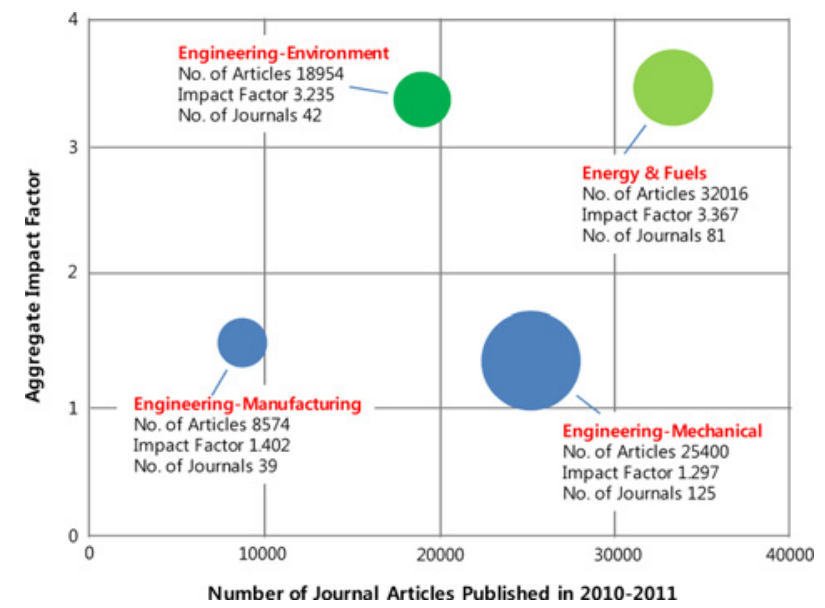

Fig. 2 Comparison of journal's impact factors in four research areas manufacturing, mechanical, environmental, and energy \& fuels. Data is obtained from Journal Citation Report $2012^{9}$ 


\section{Evaluation of journals based on H-Index}

Although impact factor is a reasonable measure for a journal, it is an average which can mislead researchers by simply calculating the ratio of the cited number of papers to the total number of published papers. The cited number can affect impact factor greatly, particularly if the number of papers are few. As a typical problem of arithmetic mean, one paper with a large number of citations will result in over-estimated impact while a couple of papers with zero citation will make under-estimated impact. Review papers also affect impact factor greater than regular research papers because of the number of papers used in impact factor calculation, i.e. denominator is small while citation of review papers is usually more.

Thus in this research, journals are evaluated by H-Index of original research papers without including review papers. H-Index was developed by Jorge E. Hirsch, and it represents impact of highly cited papers as well as the effect of number of papers. ${ }^{10}$ As shown in Fig. 3, H-Index is determined when the number of highly cited papers equals the number of papers (For example the top $5^{\text {th }}$ paper by number of citation was cited at least 5 times by other papers, the H-Index is 5).

Besides Web of Science, Google Scholar and Scopus also offer tools to calculate H-Index although covered publication can be somewhat

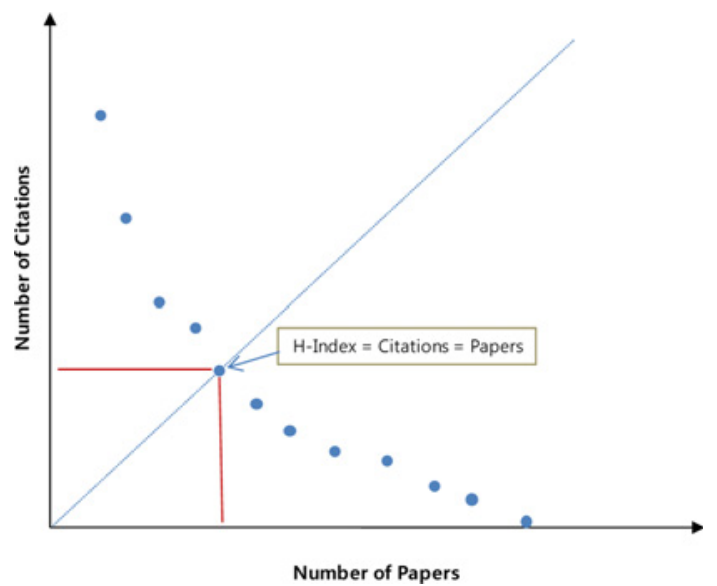

Fig. 3. Calculation of H-Index (redrawn from ${ }^{10}$ )

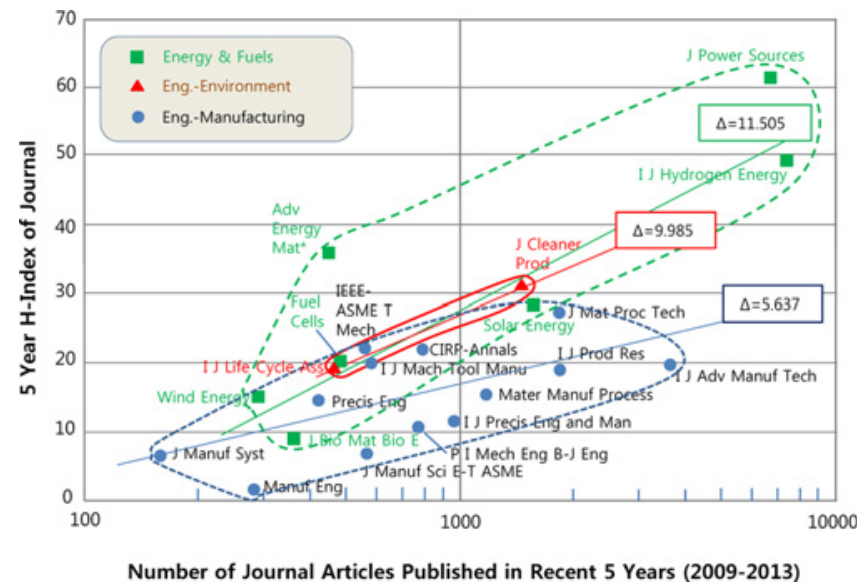

Fig. 4 Comparison of journals in three research areas related to green technologies. The gradients of Energy \& Fuels, EngineeringEnvironment, and Engineering-Manufacturing are 11.505, 9.985, and 5.637 respectively different. ${ }^{11}$ While H-Index is often used to evaluate researcher's performance, the H-Index of journals and research areas are evaluated. Fig. 4 shows data of H-Index vs. number of articles published in recent 5 years (2009.1.1-2013.12.16) using Web of Science database. ${ }^{12}$ Calculation of $\mathrm{H}$-index was performed as follows:

1. Total number of papers of a specific journal or research area was searched by Web of Science. (The review papers and editorials were excluded in this search)

2. Plot $\mathrm{x}$-axis in log scale since the number of papers can vary in different order of magnitude (see Fig. 4).

3. The same assumption applied for evaluation - the number of paper ( $\mathrm{x}$ value) represents 'importance' of the journal or importance of research areas while H-Index (y-value) represents 'attention' by researchers.

The most recent 5 year data were selected in order to have enough time for the papers to be read and cited by fellow researchers. As shown in Fig. 4, groups of journals in similar subject areas can be distinguished by overall locations taken in the plot. Compared with traditional manufacturing journals, environment-related journals show a slight increase in the number of published papers (x-values) with higher H-Index (y-values), and energy/ fuel-related journals show the highest $\mathrm{x}$ and $\mathrm{y}$ values among the three groups.

Interestingly the data show linearly fitted trend lines for all three cases with different gradients. The gradient increases in the order of manufacturing, environment, and energy/fuel, and this trends probably coincide with researchers' interest in these journals. It may be concluded that H-Index is proportional to the log of the number of papers, and in other words, certain research areas draw similar ratio in H-Index to the $\log$ of the number of papers.

\section{Evaluation of Research Areas in Green Manufacturing by H-Index}

In order to evaluate and compare graphically each research area related to green manufacturing, another plot was drawn. Fig. 5 shows H-Index vs. number of articles in recent 5 years for the 'research area'. From the Web of

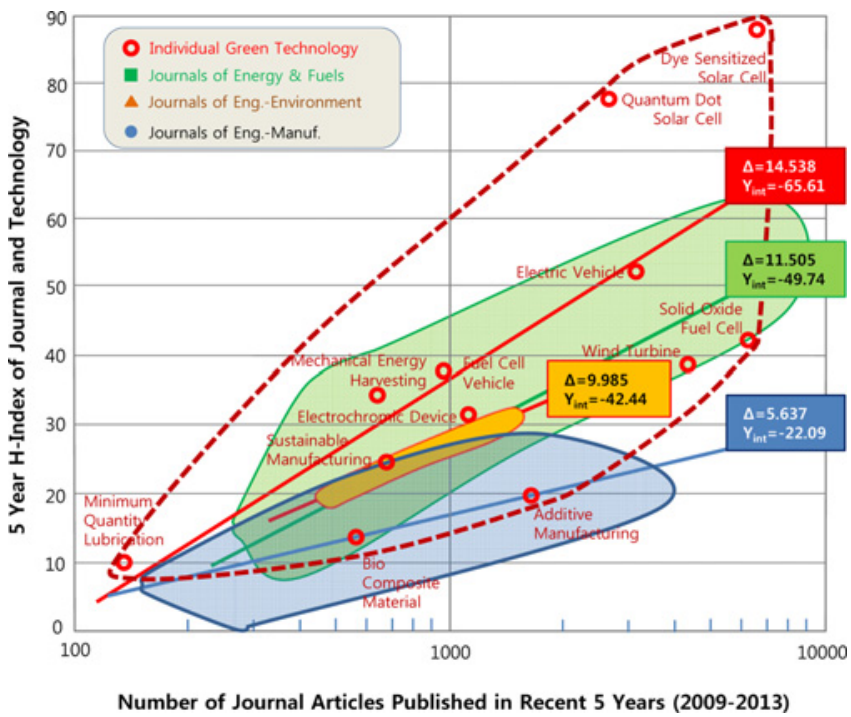

Fig. 5 Comparison of research areas in green manufacturing with journals in related topics. The gradient of selected Green Technology (14.538) is higher than the gradient of three journal areas 
Science, papers in a specific 'subject' area are searched and selected for further analysis and the number of papers under the subject as well as $\mathrm{H}-$ Index can be viewed in the Web of Science. For example, H-Index of 'fuel cell vehicle' rises to 38 as the top $38^{\text {th }}$ most cited paper in fuel cell vehicle research cited at least 38 times by other journal papers. Again, original research articles were only counted, but reviews and editorials were excluded. The subjects were chosen to be related to manufacturing and design of green technology. Some selected keywords related to green manufacturing also show a group along the trend line with the equation of $y=14.538 \ln (x)-65.61$ where $x$ is the number of journal articles published in recent 5 years, and $\mathrm{y}$ is the H-Index of technology. The gradient of the trend line is a characteristic of research areas related to energy-environment-manufacturing, and, interestingly, the gradient of the trend line (14.538) is slightly higher than the slope (11.505) of the journals in energy \& fuel area. This is probably because of the outstanding H-Index of Dye Sensitized Solar Cell.

As the same in evaluation of journal, a larger $\mathrm{x}$-axis signifies an increase in the number of papers and experimentalists in the research area, and a higher H-Index means the more attention received by other researcher to the research area.

\section{Development Stages of Journal and Technology}

From the characteristics of number of citation and H-Indexes, the overall stages in development of journal and technology can be depicted in Fig. 6 .

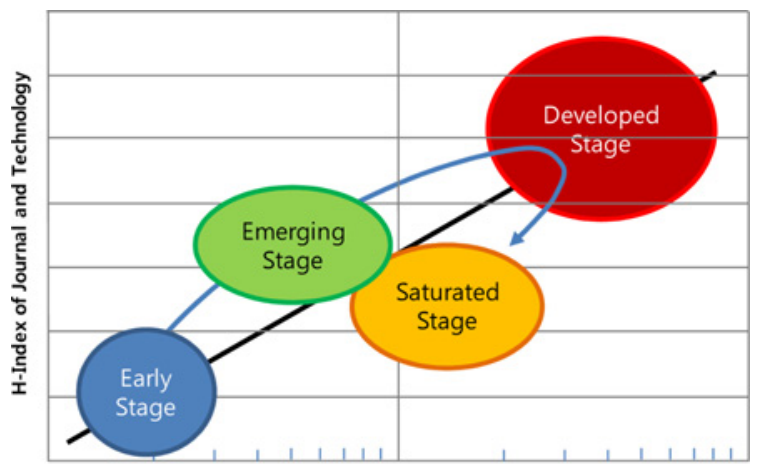

Number of Journal Articles Published in Recent 5 Years

Fig. 6 A schematic diagram on development stages of different journals and technologies based on H-Index and number of publication

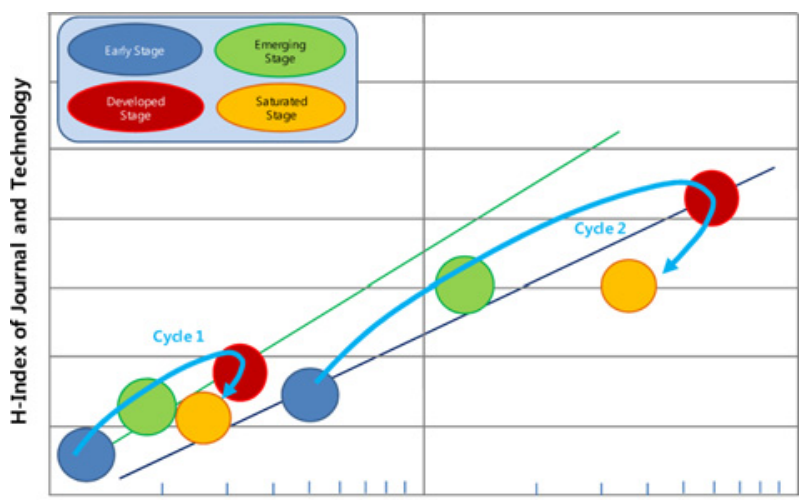

Number of Journal Articles Published in Recent 5 Years

Fig. 7 A schematic diagram on development stages of journals and technologies based on H-Index and number of publications
Based on the relative location in Fig. 6, the development of journal and technology can be simplified as proposed by four stages as follows:

Early Stage: the research topic is new implying little researcher exposure and attention to the emerging area - located at lower left corner.

Emerging Stage: the number of researchers is not numerous in number yet, but the attention by other researchers is high - located along the trend line of green manufacturing with H-Indexes above average values.

Developed Stage: a large number of researchers work on the subject, and this becomes a well appreciated research area - located upper right corner.

Saturated Stage: many researchers still continue on research, but not much issues are interesting any more for other researchers - along the trend line with relatively lower H-Index.

The development of the stages may look like a cycle if we see the relative locations in the H-Index plot (Fig. 6). Depending on the potential size of certain research fields or journal, the absolute values in number of paper and H-Index can vary as shown in Fig. 7. In addition, selection of keywords for the subject of interest should be reasonable. For example, searching by keyword of 'solar cell' or 'manufacturing,' resulted in ten thousands of papers, and most research databases cannot compute H-Index values.

\section{Conclusions}

The stages of technology development in each technology as well as technical journal were evaluated by using two measureable parameters from the Web of Science - the number of papers and H-Index. Green manufacturing technologies became important research areas with significant potential impact on human lives today and even more in the future. Further, understanding the status of development of each green technology seems relevant at the time of launching new journal, IJPEM-GT. The analysis shows the timely need for journals in green technology focusing on manufacturing. Since the current analysis is not based on extensive data collected over time, there is potential for the proposed stages in technology development to be monitored and verified in the future. However, researchers can utilize the proposed comparative method to distinguish numerous emerging technologies.

\section{ACKNOWLEDGEMENT}

This work was designed to celebrate the inauguration of IJPEM-GT, and kindly supported by National Research Foundation (NRF-20100029227) and LG Yonam Foundation of Korea. Author would like to thank co-editors-in-chief, editors and members of editorial board of IJPEM-GT, and presidents and directors of Korean Society of Precision Engineering (KSPE), especially Professor Chong-Nam Chu, Doctor Eung-Sug Lee and Doctor Hon-Zong Choi, Professor Sun-Kyu Lee, Professor Dong-Yol Yang and Professor Seung-Woo Kim for their leadership in journal inauguration. In addition, supports and cooperation by Mr. Byeongkwon Lee and Miss Young Sim Kim at KSPE, Professor C. S. Lee at Hanyang University, Doctor Won-Shik 
Chu and Doctor Varsha Khare at Seoul National University, Doctor Mark de Jongh at Springer, and Ms. Chang Liu at Thomson Reuter are greatly appreciated. The deepest gratitude is expressed to the providence of God from the initiation of new journal till the production of the inaugural issue.

\section{REFERENCES}

1. Keeling, C. D., "The Concentration and Isotopic Abundances of Carbon Dioxide in the Atmosphere," Tellus, Vol. 12, No. 2, pp. 200203, 1960 .

2. Folger, T., "Rising Seas," National Geographic, September, pp. 3059, 2013.

3. United Nations Population Fund, "State of World Population 2011," 2011.

4. Kanu, M., Physics of The Future, Anchor Books, pp. 243-272, 2011.

5. Park, C. W., Kwon, K. S., Kim, W. B., Min, B. K., Park, S. J., and et al., "Energy Consumption Reduction Technology in Manufacturing - A Selective Review of Policies, Standards, and Research," Int. J. Precis. Eng. Manuf., Vol. 10, No, 5, pp. 151-173, 2009.

6. Ahn. S. H., "Preface for a Special Issue on Green Manufacturing and Applications" Int. J. Precis. Eng. Manuf., Vol. 13, No. 7, Paper No. 1027, 2012.

7. Ahn. S. H., Chun, D. M., and Chu, W. S., "Perspective to Green Manufacturing and Applications" Int. J. Precis. Eng. Manuf., Vol. 14, No. 6, pp. 873-874, 2013.

8. Hype cycle, "Hype Cycles 2013," http://www.gartner.com/ technology/research/hype-cycles.html (Accessed 24 Dec. 2013)

9. THOMSON REUTERS "Journal Citation Report," http:// thomsonreuters.com/journal-citation-reports.html (Accessed 24 Dec. 2013)

10. Hirsch, J. E., “An Index to Quantify an Individual's Scientific Research Output,” PNAS, Vol. 102, No. 46, pp. 16569-16572, 2005.

11. Meho, L. I. and Yang, K., "Impact of Data Sources on Citation Counts and Rankings of LIS Faculty: Web of Science vs. Scopus and Google Scholar," Journal of the American Society for Information Science and Technology, Vol. 58, No. 13, pp. 21052125, 2007.

12. THOMSON REUTERS "Web of Science," http://thomsonreuters. com/web-of-science.html (Accessed 24 Dec. 2013) 